\title{
How does inflammation contribute to pulmonary hypertension?
}

\author{
Rahul Kumar and Brian Graham
}

\begin{abstract}
Affiliation: Program in Translational Lung Research, Dept of Medicine, Anschutz Medical Campus, University of Colorado, Aurora, CO, USA.

Correspondence: Brian Graham, Program in Translational Lung Research, University of Colorado, Dept of Medicine, Anschutz Medical Campus, Building RC2, 9th floor, 12700 East 19th Avenue, Aurora, C0 80045, USA. E-mail: brian.grahamवucdenver.edu
\end{abstract}

@ERSpublications

Blocking inflammation could be a curative approach in pulmonary vascular diseases http://ow.ly/dW5M30hB6aj

Cite this article as: Kumar R, Graham B. How does inflammation contribute to pulmonary hypertension? Eur Respir J 2018; 51: 1702403 [https://doi.org/10.1183/13993003.02403-2017].

Pathogenic drivers of the pulmonary vascular disease that results in pulmonary arterial hypertension $(\mathrm{PAH})$ are currently unclear, but there are many reasons to suspect that inflammation is a major contributor. Clinically, PAH is a complication of multiple autoimmune diseases including scleroderma and systemic lupus erythematosus, suggesting dysregulated immunity can trigger the vascular disease [1-3]. $\mathrm{PAH}$ can also complicate several infectious diseases, including HIV and schistosomiasis, suggesting there could be off-target effects of immune upregulation which inadvertently damage the pulmonary vasculature. Patients with these pro-inflammatory aetiologies often have systemic vascular diseases, including digital ischaemia in scleroderma and portal hypertension in schistosomiasis $[4,5]$, suggesting the same inflammatory stimuli can lead to diverse vascular pathologies.

Experimentally, pulmonary hypertension $(\mathrm{PH})$ can be triggered by exposing animals to immunogenic stimuli, including HIV, schistosomiasis, ovalbumin, interleukin (IL)-6 overexpression, and Fra-2 overexpression [6-10]. In these models, blocking the inflammatory trigger, or the downstream inflammatory cascade such as Type 2 inflammation in schistosomiasis, can prevent the pulmonary vascular disease phenotype [8-13].

However, blocking inflammation has only been shown to be of clinical benefit in one specific form of highly inflammatory disease: systemic lupus erythematosus-associated PAH [14]. Despite this evidence of inflammation underlying disease pathogenesis, why has targeting inflammation in PAH been otherwise unsuccessful? There are several possibilities. First and foremost, the precise inflammation present in human PAH is complex and unclear, with probable simultaneous presence of different types of inflammation which both augment and suppress the vascular disease. Generalised immune suppression would target both deleterious and compensatory pathways, and thus not effectively inhibit pathological drivers while sparing beneficial mechanisms. Alternatively, the timing could be wrong: inflammation could trigger the disease, but no longer be pathogenic in established disease. Lastly, inflammation could be an

Received: Nov 202017 | Accepted after revision: Dec 022017

Support statement: B. Graham has received research funding from American Thoracic Society/Pulmonary Hypertension Association (research fellowship), Gilead Sciences (Research Scholars Program in Pulmonary Arterial Hypertension) and NIH/NHLBI (grant numbers P01HL014985, R01HL135872 and R03HL133306). Funding information for this article has been deposited with the Crossref Funder Registry

Conflict of interest: Disclosures can be found alongside this article at erj.ersjournals.com

Copyright CERS 2018 
epiphenomenon, which occurs in parallel but doesn't causally drive the vascular disease, or develops late as a consequence of medial and intimal pathology.

Into the knowledge gap of understanding regarding what inflammation is actually present in human pathology steps the study by MARSH et al. [15] in this issue of the European Respiratory Journal. The authors apply flow cytometry and computational techniques to generate a global view of distinct inflammatory cell signatures in the pulmonary arteries of 16 subjects with idiopathic pulmonary arterial hypertension (IPAH) and 15 lung donors as control tissue. The primary findings included the observation that in control specimens $64 \%$ of all leukocytes $\left(\mathrm{CD} 45^{+}\right.$cells) were of myeloid lineage (neutrophils and monocytes) and 15\% were of lymphoid lineages (primarily CD4 and CD8 T-cells); in PAH the ratio shifted with the myeloid cells decreasing to $52 \%$ while the lymphoid cells enriched to $31 \%$. Further, these PAH lymphoid cells consisted of CD4, CD8 and $\gamma \delta$ T-cell subsets.

The study by MARSH et al. [15] nicely complements the prior work by SAVAI et al. [16], which used immunostaining approaches to characterise the inflammatory cells in IPAH lungs. Flow cytometry has the advantages of using many simultaneous markers to highly characterise single cells, and more readily quantifying relative proportions of different cell types. In contrast, immunostaining allows analysis of cells within preserved tissue architecture. The work by SAVAi et al. [16] thus focused on the vascular compartment, sometimes resulting in slightly different data. SAVAI et al. [16] also identified a significant increase in CD4 and CD8 T-cells in the adventitial space. A third study also reported an increase in the density of T-cells in the lungs of patients with schistosomiasis-associated PAH [17]. Experimental studies in animals, complementing these observational human data, have suggested CD4 T-cells are pathological in promoting hypoxia-induced PH (T-helper (Th)17 CD4 T-cells) $[18,19]$ and schistosomiasis-induced PH (Th2 CD4 T-cells) [11].

MARSH et al. [15] also identified an increase in dendritic cells in the lungs of IPAH patients, of both myeloid and plasmacytoid subtypes, as well as an increase in circulating plasmacytoid dendritic cells. SAVAI et al. [16] also reported an increase in dendritic cells. The function of dendritic cells here is unknown. Employing the power of flow cytometry, MARSH et al. [15] found an increase in CD1a expression in some of these cells, consistent with an activated phenotype that can secrete IL-12 and present antigen to activate CD4 T-cells. These dendritic cells could thus causally contribute to the increase in T-cells noted earlier.

Both MARSH et al. [15] and SAVAI et al. [16] reported an increase in mast cells in PAH lungs, as have prior publications $[16,20]$. In animal studies, blocking mast cells is protective in models of $\mathrm{PH}[21,22]$, implicating these cells as likely to be pathological.

Both studies also reported a change in macrophage populations in patients with IPAH. SAVAI et al. [16] noted a substantial increase in the density of adventitial $\mathrm{CD} 68^{+}$macrophages and $\mathrm{CD} 14^{+}$macrophages/ monocytes, whereas MARSH et al. [15] report an increase in activated (CD1a ${ }^{+} \mathrm{HLA}^{+}$) macrophages [23]. Experimentally, depleting macrophages, such as via clodronate, protects against hypoxia-induced $\mathrm{PH}[24$, 25], and blocking the recruitment of circulating monocytes (by CCR2 deficiency) protects against schistosomiasis-induced PH [12]. Interstitial macrophages are prominent sources of pathological leukotriene $\mathrm{B}_{4}$ in $\mathrm{PH}$ [26], and probably have other deleterious functions [27].

Along with these increases in pro-inflammatory cell density, there may be a reduction in anti-inflammatory cells, particularly regulatory T-cells (Tregs). SAVAI et al. [16] reported a decrease in anti-inflammatory FoxP3 ${ }^{+}$monocytes in IPAH lung, of which some were Tregs. MARsH et al. [15] now indirectly support these data with the finding of a higher number of plasmacytoid dendritic cells, which may decompensate for a decreased number of Tregs [28]. Experimentally, absence of Tregs (such as in the athymic rat) increases susceptibility to vascular endothelial growth factor receptor 2 blockade by SU5416, and reconstituting Tregs is protective in this model [29]. One of the potential mechanisms of Treg-induced protection is upregulation of bone morphogenetic protein type 2 receptor expression in vascular endothelial cells and macrophages, which is mutated in many heritable cases of PAH and suppressed in idiopathic disease [29]. Thus, future anti-inflammatory therapies probably need to at least spare and ideally augment Tregs.

What are the next steps towards the long-term goal of developing effective treatments for PAH by targeting inflammation? We suggest first deepening our understanding of the role of inflammation in the pathology of $\mathrm{PAH}$, to permit more precise targeting of causal mechanisms. In particular, answering the following questions will be helpful.

1) Beyond describing the density and localisation of immune cells in human $\mathrm{PH}$, what are the phenotypes of these cells? For example, are the CD4 T-cells activated, and if so, what phenotype are they (Th1/Th2/ Th17)? 
2) What are the critical interactions between the different cell populations? For example, are the CD1a ${ }^{+}$ dendritic cells actually presenting antigen to CD4 T-cells, and if so, what is the antigen?

3) Does the increased density of leukocytes arise from recruitment of circulating cells, or proliferation of endogenous cells? For example, it has recently been reported that there are distinct subsets of interstitial macrophages in rodents [30]: do these subsets have parallels in human tissue, and if so, which are involved in $\mathrm{PH}$ ?

4) The actual rise in pulmonary vascular resistance results from intima and media proliferation, hypertrophy and vasoconstriction: do inflammatory cells, generally located in the adventitia [16], directly induce medial and intimal pathology, and if so, how? Or do they function through a third party, such as the fibroblast?

5) Do inflammatory animal models of $\mathrm{PH}$ adequately recapitulate critical immune drivers of clinical disease?

6) Does delayed targeting of the inflammation reverse established disease in animal models of inflammatory-PH?

7) How does inflammation evolve as the disease progresses, from at-risk and preclinical into early and then late pulmonary vascular disease?

Despite these uncertainties, the field has moved ahead with attempting to target inflammation clinically. One example of more selective targeting of pathological inflammation is the ongoing study of rituximab in scleroderma-associated PAH (ClinicalTrials.gov identifier: NCT01086540). In the future, the field may need to consider preventative approaches, suppressing inflammation in at-risk individuals (such as those with scleroderma) to prevent the development of pulmonary vascular disease. Overall, blocking inflammation remains an attractive target in $\mathrm{PH}$, as it may actually underlie the disease pathology, and thus could eventually be a truly curative approach.

\section{References}

1 Dib H, Tamby MC, Bussone G, et al. Targets of anti-endothelial cell antibodies in pulmonary hypertension and scleroderma. Eur Respir J 2012; 39: 1405-1414.

2 Rabinovitch M, Guignabert C, Humbert M, et al. Inflammation and immunity in the pathogenesis of pulmonary arterial hypertension. Circ Res 2014; 115: 165-175.

3 Trad S, Amoura Z, Beigelman C, et al. Pulmonary arterial hypertension is a major mortality factor in diffuse systemic sclerosis, independent of interstitial lung disease. Arthritis Rheum 2006; 54: 184-191.

4 McMahan ZH, Hummers LK. Systemic sclerosis-challenges for clinical practice. Nat Rev Rheumatol 2013; 9: 90-100.

5 Wilson MS, Mentink-Kane MM, Pesce JT, et al. Immunopathology of schistosomiasis. Immunol Cell Biol 2007; 85: $148-154$.

6 George MP, Champion HC, Simon M, et al. Physiologic changes in a nonhuman primate model of HIV-associated pulmonary arterial hypertension. Am J Respir Cell Mol Biol 2013; 48: 374-381.

7 Graham BB, Bandeira AP, Morrell NW, et al. Schistosomiasis-associated pulmonary hypertension: pulmonary vascular disease: the global perspective. Chest 2010; 137: 20S-29S.

8 Steiner MK, Syrkina OL, Kolliputi N, et al. Interleukin-6 overexpression induces pulmonary hypertension. Circ Res 2009; 104: 236-244.

9 Maurer B, Busch N, Jungel A, et al. Transcription factor fos-related antigen-2 induces progressive peripheral vasculopathy in mice closely resembling human systemic sclerosis. Circulation 2009; 120: 2367-2376.

10 Daley E, Emson C, Guignabert C, et al. Pulmonary arterial remodeling induced by a Th2 immune response. J Exp Med 2008; 205: 361-372.

11 Kumar R, Mickael C, Chabon J, et al. The causal role of IL-4 and IL-13 in Schistosoma mansoni pulmonary hypertension. Am J Respir Crit Care Med 2015; 192: 998-1008.

12 Kumar R, Mickael C, Kassa B, et al. TGF-beta activation by bone marrow-derived thrombospondin-1 causes Schistosoma- and hypoxia-induced pulmonary hypertension. Nat Commun 2017; 8: 15494.

13 Tcherakian C, Couderc LJ, Humbert M, et al. Inflammatory mechanisms in HIV-associated pulmonary arterial hypertension. Semin Respir Crit Care Med 2013; 34: 645-653.

14 Kommireddy S, Bhyravavajhala S, Kurimeti K, et al. Pulmonary arterial hypertension in systemic lupus erythematosus may benefit by addition of immunosuppression to vasodilator therapy: an observational study. Rheumatology (Oxford) 2015; 54: 1673-1679.

15 Marsh LM, Jandl K, Grünig G, et al. The inflammatory cell landscape in the lungs of patients with idiopathic pulmonary arterial hypertension. Eur Respir J 2018; 51: 1701214.

16 Savai R, Pullamsetti SS, Kolbe J, et al. Immune and inflammatory cell involvement in the pathology of idiopathic pulmonary arterial hypertension. Am J Respir Crit Care Med 2012; 186: 897-908.

17 Mauad T, Pozzan G, Lancas T, et al. Immunopathological aspects of schistosomiasis-associated pulmonary arterial hypertension. J Infect 2014; 68: 90-98.

18 Hashimoto-Kataoka T, Hosen N, Sonobe T, et al. Interleukin-6/interleukin-21 signaling axis is critical in the pathogenesis of pulmonary arterial hypertension. Proc Natl Acad Sci USA 2015; 112: E2677-E2686.

19 Maston LD, Jones DT, Giermakowska W, et al. Central role of T helper 17 cells in chronic hypoxia-induced pulmonary hypertension. Am J Physiol Lung Cell Mol Physiol 2017; 312: L609-L624. 
20 Caslin AW, Heath D, Madden B, et al. The histopathology of 36 cases of plexogenic pulmonary arteriopathy. Histopathology 1990; 16: 9-19.

21 Breitling $\mathrm{S}$, Hui $\mathrm{Z}$, Zabini $\mathrm{D}$, et al. The mast cell-B cell axis in lung vascular remodeling and pulmonary hypertension. Am J Physiol Lung Cell Mol Physiol 2017; 312: L710-L721.

22 Aiello RJ, Bourassa PA, Zhang Q, et al. Tryptophan hydroxylase 1 inhibition impacts pulmonary vascular remodeling in two rat models of pulmonary hypertension. J Pharmacol Exp Ther 2017; 360: 267-279.

23 Pullamsetti SS, Kojonazarov B, Storn S, et al. Lung cancer-associated pulmonary hypertension: role of microenvironmental inflammation based on tumor cell-immune cell cross-talk. Sci Transl Med 2017; 9: eaai9048.

24 Frid MG, Brunetti JA, Burke DL, et al. Hypoxia-induced pulmonary vascular remodeling requires recruitment of circulating mesenchymal precursors of a monocyte/macrophage lineage. Am J Pathol 2006; 168: 659-669.

25 Vergadi E, Chang MS, Lee C, et al. Early macrophage recruitment and alternative activation are critical for the later development of hypoxia-induced pulmonary hypertension. Circulation 2011; 123: 1986-1995.

26 Tian W, Jiang X, Tamosiuniene R, et al. Blocking macrophage leukotriene b4 prevents endothelial injury and reverses pulmonary hypertension. Sci Transl Med 2013; 5: 200 ra117.

27 Florentin J, Dutta P. Origin and production of inflammatory perivascular macrophages in pulmonary hypertension. Cytokine 2017; 100: 11-15.

28 Audiger C, Rahman MJ, Yun TJ, et al. The importance of dendritic cells in maintaining immune tolerance. $J$ Immunol 2017; 198: 2223-2231.

29 Tamosiuniene R, Tian W, Dhillon G, et al. Regulatory T cells limit vascular endothelial injury and prevent pulmonary hypertension. Circ Res 2011; 109: 867-879.

30 Gibbings SL, Thomas SM, Atif SM, et al. Three unique interstitial macrophages in the murine lung at steady state. Am J Respir Cell Mol Biol 2017; 57: 66-76. 